\title{
3 Research Square

\section{Dietary intakes and their association with weight status in male and female school children in South India: A cross-sectional study}

Sumathi Swaminathan ( $\nabla$ sumathisjri@gmail.com )

St John's Research Institute https://orcid.org/0000-0002-4006-1049

\section{Sumithra Selvam}

St John's Research Institute

Tinku Thomas

St John's Medical College

Krishnaswamy G Jayachitra

St John's Research Institute

Anura V Kurpad

St John's Medical College

\section{Research}

Keywords: 24-hour dietary recall, underweight, overweight, school children

Posted Date: April 20th, 2020

DOI: https://doi.org/10.21203/rs.3.rs-22188/v1

License: (9) This work is licensed under a Creative Commons Attribution 4.0 International License. Read Full License 


\section{Abstract}

\section{Background}

With India going through a nutrition transition evaluating food consumption of children is important. The present analysis was done to cross-sectionally examine the diets of school-aged children by sex and weight status.

\section{Methods}

Urban school-going children 8-15 years of age, representing all strata of socio-economic status were recruited through stratified quota sampling. Dietary intake was assessed by three intervieweradministered 24-hour dietary recalls. The proportion with inadequate intakes for macro- and micronutrients and percentage energy intake of macronutrients below and above the Acceptable Macronutrient Distribution Range (AMDR) were compared between sexes. Association of dietary intake with weight status were examined by multinomial logistic regression in boys and girls separately with the reference category being the highest tertile of each food group intake.

Results

Totally, 634 children were recruited $(13.7 \%$ boys, $15.6 \%$ girls underweight; $18.8 \%$ boys, $18.5 \%$ girls overweight). In general, boys had significantly higher mean intakes of all nutrients $(p<0.05)$ except for vitamin B $12(0.96 \mu \mathrm{g}$ in boys versus $0.87 \mu \mathrm{g}$ in girls, $\mathrm{p}=0.055)$ and vitamin A (225.4 $\mu \mathrm{gRAE}$ in boys and $222.2 \mu \mathrm{gRAE}$ in girls, $p=0.073)$. The prevalence of inadequate intake was the highest for vitamin $A(96.8 \%$ in boys vs $94.8 \%$ in girls, $p=0.152$ ). The proportions of inadequacy were significantly higher in girls for all nutrients $(p<0.05)$, except for folate and vitamin A. High carbohydrate intake (OR:3.11; 95\% Cl:1.55, 6.24, $\mathrm{p}=0.002)$ and low fat intake (OR:2.15; $95 \% \mathrm{Cl}: 1.06,4.35, \mathrm{p}=0.041)$ were significantly associated with underweight in girls but not for boys. After adjusting for age and total energy intake, lower intake of vegetables and higher intake of fruits were significantly associated with underweight boys while, lower intake of root vegetables, nuts, milk products and added sugar were associated with underweight girls. A higher proportion of overweight boys was observed in the lowest tertile of pulse intake and lower proportion in the lowest tertile of nut intake. Overweight girls were more likely to be in the lowest tertile of meat intake.

Conclusions

Children's diets need to be improved to meet nutrient requirements. Promotion of healthy diets in children which reduce prevalence of underweight and arrest increase in overweight is required.

\section{Background}

Globalization and urbanization have influenced diets of adults and children in terms of food options and choices in both developing and developed countries (1-3). Over the past few decades, the diets of 
children have changed rapidly and this has been attributed to the ongoing nutrition transition (4-6). Present day diets have led to an increased consumption of higher fat and sodium and less of fibre and essential micronutrient intakes mainly through consumption of processed foods, resulting in the triple burden of malnutrition (undernutrition, overnutrition and micronutrient deficiencies) (3). Diets of children in developing countries including India, continue to be of poor dietary quality with poor dietary diversity $(7,8)$. A study conducted across 9 to 11 -year-old children across 12 countries in the world including India, showed an association of lower income or levels of parental education with higher consumption of unhealthy foods and lower consumption of healthy foods patterns irrespective of whether children were from countries with high or low development; this was attributed to easy availability because of low costs of unhealthy foods (9). Childhood is a critical period when dietary habits formed have a bearing on later adult health outcomes particularly of chronic diseases (8). Considering these factors, it is essential to evaluate dietary intakes of children to understand what they currently eat so that diets can be improved to meet nutrient requirements. Evaluating and ensuring adequate intakes of both macro- and micro-nutrients is important as it is possible that the quality of intake is not adequate to meet both the macro- and micronutrient requirements.

By assessing nutrient intakes the prevalence of inadequate intakes of nutrients for groups or populations can be determined (10). Such monitoring is essential in a country like India where deficiencies of several macro-and micronutrient deficiencies exist and are attributed largely to dietary insufficiencies. The type of diet eaten is also influenced by decreased bio-availability of some micronutrients due to inherent inhibitors in the foods eaten as for example, phytates (11). Evidence from repeated national intake surveys conducted by the National Nutrition Monitoring Bureau largely in the rural areas, show highest deficits in intake for folic acid followed by iron and riboflavin and then thiamine and niacin with deficits increasing with increase in age in children (12). Such data is however, lacking in urban children in India.

The period of childhood and adolescence is critical in growth and development. With India facing a triple burden of malnutrition with under-nutrition, over-nutrition and micronutrient deficiencies observed, it becomes relevant to assess dietary intakes of this population. Children 6 to 18 years of age constitute about $27.5 \%$ of the total population of India and $23.9 \%$ of population of the state of Karnataka as per the latest census of India (13). The effects of nutrition transition are likely to be observed in diets of urban children where availability, accessibility and affordability to a variety of foods is presumably higher. This has so far not been studied in detail in India. The objective of this analysis was to examine dietary intakes of urban male and female school children including the level of inadequacy and to compare dietary intakes between sexes based on their weight status.

\section{Methods}

\section{Study population and sample size}

In a cross-sectional study, children 8 to 15 years were recruited from schools in urban Bangalore in the state of Karnataka, India from January to October 2015. A stratified quota sampling design based on 
socio-economic level of children attending schools and their annual fee (low, medium and high fees) was employed. Thus, a total of 7 schools were identified. The annual fees of each school were obtained to classify the socio-economic status (SES) as catering to students from low, middle and high SES groups.

With hitherto unpublished data in school children on dietary intake, micronutrient inadequacy for iron, folate, thiamine, riboflavin, niacin and vitamin $\mathrm{B}_{6}$ and $\mathrm{B}_{12}$ ranged between 30 and $56 \%$. Hence assuming an inadequacy level of intake of micronutrients of $45 \%$, the sample size required to estimate at a precision of $15 \%$ and a confidence interval of $95 \%$ was 210 per strata (total of 630 children). In total to achieve the proposed sample size 3 low SES, 2 middle SES and 2 high SES schools were contacted and all schools permitted their children to participate in the study.

Ethical approval was obtained from the Institutional Ethics Committee of the St John's Medical College, Bangalore. The management of the school or the principals were contacted for permissions to conduct the study. Written informed consent was from parents and oral assent from children were obtained. A target of 90 children at each age from 8 to 15 years was proposed to be achieved to attain the required sample size of 630 children by recruiting based on date of consent received. A total of 2065 consent forms were distributed in the 7 schools, out of which 837 were willing to participate in the study and 634 were finally recruited. In total, 203 children were not recruited, 164 of them due to the reason that the target of 90 children were achieved for the particular age (as for example 8 to 9 years), 21 due to incomplete consent forms, 2 were above the age of 15 years, 4 below the age of 8 years and 12 were absent during the period of study in the school.

\section{Demography and dietary intake}

Demographic data on age and sex of the child, education and occupation of both parents were collected. Based on age, children were categorized as below 11 years of age and $\geq 11$ years of age, as age 11 marks the onset of adolescence. Education of parents was categorized as up to primary which included those uneducated and those who had availed up to grade 5 of education, secondary which included a further 7 years of education and university level.

For each child, dietary intake was assessed by three 24-hour dietary recalls as usual intakes can be calculated. Further, Burrows et al (14) indicated that 24-hour recalls collected over 3 days gave the best estimate of energy intake in children 4 to 11 years of age. Two non-consecutive weekday recalls, and one weekend/holiday recall were taken by trained personnel from the child using an interviewer administered questionnaire. The 24-hour recall was administered individually to each child by trained interviewers with the subject first listing the foods and beverages consumed during the preceding day, including vitamin and mineral supplements, followed by the reporting of portion size using food portion size aids and then probing for forgotten foods after which the whole recall was reviewed with the subject.

The data collected was entered into a software created using the food composition database developed specifically for this purpose (15) and macronutrients (energy, protein, fat, carbohydrates) and 
micronutrients (iron, thiamine, riboflavin, niacin, vitamin $B_{6}$, vitamin $B_{12}$, folate and vitamin $A$ ) values for each of the 3 recalls were obtained. To estimate usual intake distributions and obtain the proportion at risk of inadequate intake of protein, iron, thiamine, riboflavin, niacin, vitamin $B_{6}$, vitamin $B_{12}$, folate and vitamin $A$, the within- and between-person variability was determined. The day-to-day variability in intakes was partially removed by fitting a measurement error model to daily log transformed intake data to minimize bias in estimates of prevalence of inadequacy using the Estimated Average Requirement (EAR) (Supplementary table S1). All statistical adjustments were done for the distribution of intake of each individual in the group as per the National Research Council's approach proposed by Institute of Medicine $(\mathrm{IOM})(16)$.

The proportion of children with inadequate intake of the nutrients was determined based on age and sex specific Estimated average requirement $(E A R)$ as per recommendations by $\operatorname{IOM}(16,17)$ for protein, thiamine, riboflavin, niacin, vitamin $B_{6}$, vitamin $B_{12}$, folate and vitamin $A$ using $E A R$ cut point method $(16,18)$. To identify children at risk of inadequate intake for iron, the estimated average requirement recently provided in a publication on iron requirements in Indian children was used (19). The risk of inadequate intake of iron was computed by the probability method which applies a continuous riskprobability function to each individual's estimated intake and then averages the individual probabilities across the population or group.

Further, macronutrient intake were categorised based on acceptable macronutrient distribution range (AMDR) as defined by the Institute of Medicine for children 4 to 18 years of age (16). Carbohydrate intakes 45 to $65 \%$ of energy, protein intake between 10 to $30 \%$ of energy and fat between 25 and $35 \%$ of energy were considered as adequate intake; values below $45 \%, 10 \%$ and $25 \%$ of energy for carbohydrate, protein and fat respectively, were considered as "below AMDR", values above $65 \%, 30 \%$ and $35 \%$ of energy for carbohydrate, protein and fat were termed as "above AMDR".

Cereals, pulses, root vegetables, other vegetables, fruits, milk (milk and milk products) nuts, meat (red and white meat, fish and egg), added fats and added sugar were the food groups considered for analysis.

The nutrient intake during breakfast and the use of fortified foods which included commercially fortified foods and beverages and processed foods were examined and used for analysis. The nutrient intake consumed during breakfast was compared to the whole day's intake.

\section{Anthropometric measurements}

Height was measured to the nearest $0.1 \mathrm{~cm}$ using a stadiometer (SECA 213) and weight to the nearest 0.1 $\mathrm{kg}$ using a digital weighing scale (SECA 803). Body mass index (BMI) was computed and both the height for-age $z$ scores and the BMI-for-age $Z$ score values were obtained using the World Health Organization Anthroplus software version 1.0.2 (WHO, Geneva, Switzerland) using the reference data for school aged children (20). Children were then categorized by actual weight status as overweight (>+1 SD), normal ( -2 to +1 SD) and underweight (<-2 SD). The categorized weight status was used for analysis. 


\section{Statistical Methods}

All categorical variables are presented as number and percentage. Continuous data were examined for normal distribution using Q-Q plots. The normally distributed continuous variables were reported as mean and standard deviation (SD) and the non-normal variables using median and quartiles.

The various sociodemographic variables such as age group ( $<11$ and $\geq 11$ years), SES (low, middle and high), maternal and paternal education, were compared between sexes using the Pearson's chi-square test or Fischer's exact test as appropriate. Anthropometric measures were compared using independent samples $\mathrm{t}$ test or Mann Whitney $\mathrm{U}$ test, as appropriate. The macronutrient intakes of energy, protein, fat and carbohydrate and the micronutrient intakes of iron, thiamine, riboflavin, niacin, vitamins $B_{12}, B_{6}$, folate and vitamin $A$ in all children and stratified by sex were compared using the Mann Whitney $U$ test. Percent protein, fat and carbohydrate of energy was computed and the comparison between sexes were performed using the independent samples $t$ test. The proportion at risk of inadequate intake of nutrients was compared between the 2 sexes using Chi square test or Fisher's Exact test as appropriate. Association between the proportion of boys and girls with intakes which were adequate, lower, and higher than the recommended AMDR with weight categories was analyzed using chi-square test and the odds ratio with $95 \%$ confidence interval has been reported. Multinomial logistic regression was performed to examine association of food group intake with BMI categories after adjustment for age and total energy intake. Adjusted odds ratios with $95 \%$ confidence intervals are reported. The proportion of children consuming fortified foods was reported. The percentage contribution of macronutrients consumed at breakfast to the whole day's intake was also calculated. A two-sided level of significance less than $5 \%$ was considered statistically significant. All analyses were performed with the SPSS program (version 25.0, SPSS, Chicago, IL, USA).

\section{Results}

A total of 634 school children were recruited. The profile of the children recruited into the study is represented in Table 1. Underweight and overweight prevalence were comparable between boys and girls, but height-for-age $z$ score was higher in boys $(p=0.001)$. 
Table 1

Profile of children recruited into the study

\begin{tabular}{|c|c|c|c|c|}
\hline Characteristic & $\begin{array}{c}\text { Total } \\
(\mathrm{n}=634)\end{array}$ & $\begin{array}{c}\text { Boys } \\
(n=308)\end{array}$ & $\begin{array}{c}\text { Girls } \\
(n=326)\end{array}$ & $P$ value \\
\hline Age & $11.2 \pm 2.1$ & $10.9 \pm 2.0$ & $11.5 \pm 2.1$ & 0.002 \\
\hline \multicolumn{5}{|l|}{ Age category } \\
\hline$<11$ years & 40.4 & 46.8 & 34.4 & \multirow[t]{2}{*}{0.001} \\
\hline$\geq 11$ years & 59.6 & 53.2 & 65.6 & \\
\hline \multicolumn{5}{|l|}{ Socio-economic status } \\
\hline Low & 33.6 & 33.8 & 33.4 & \multirow[t]{3}{*}{0.905} \\
\hline Middle & 33.3 & 32.5 & 34.0 & \\
\hline High & 33.1 & 33.8 & 32.5 & \\
\hline \multicolumn{5}{|l|}{ Maternal education level** } \\
\hline Primary schooling & 12.5 & 12.3 & 12.6 & \multirow[t]{3}{*}{0.939} \\
\hline Secondary schooling & 51.1 & 51.7 & 50.6 & \\
\hline University & 31.5 & 36.0 & 36.8 & \\
\hline \multicolumn{5}{|l|}{ Paternal education level } \\
\hline Primary schooling & 12.3 & 13.0 & 11.7 & \multirow[t]{3}{*}{0.475} \\
\hline Secondary schooling & 43.4 & 40.2 & 46.3 & \\
\hline University & 44.3 & 46.8 & 42.0 & \\
\hline \multicolumn{5}{|l|}{ Anthropometry } \\
\hline Height $(\mathrm{cm})$ & $143.5 \pm 12.2$ & $143.2 \pm 12.8$ & $143.7 \pm 11.5$ & 0.574 \\
\hline Weight (kg) & $36.8 \pm 11.4$ & $35.7 \pm 11.0$ & $37.8 \pm 11.7$ & 0.024 \\
\hline Height-for-age z score & $-0.58 \pm 1.09$ & $-0.47 \pm 1.16$ & $-0.73 \pm 0.99$ & 0.001 \\
\hline BMI-for-age z score & $-0.40 \pm 1.45$ & $-0.47 \pm 1.55$ & $-0.34 \pm 1.36$ & 0.268 \\
\hline \multicolumn{5}{|l|}{ Body mass index categories } \\
\hline Normal & 67.5 & 65.9 & 69.0 & \multirow[t]{3}{*}{0.414} \\
\hline Underweight & 13.7 & 15.6 & 12.0 & \\
\hline Overweight & 18.8 & 18.5 & 19.0 & \\
\hline \multicolumn{5}{|c|}{ Age and anthropometry are represented as Mean \pm SD. All other values are percentages } \\
\hline \multicolumn{5}{|c|}{ *Some children reported not knowing their mother's education level } \\
\hline
\end{tabular}

Among the nutrients examined, the intake of energy and all micronutrients other than vitamin $\mathrm{B}_{12}$ and vitamin A were higher in boys (Table 2). Carbohydrate, fat and protein as percent of energy were not different between the sexes. Food group intake of cereals, nuts, added fats and oils, added sugar and milk intakes were higher in boys. 
Table 2

Children's nutrient and food group intake

\begin{tabular}{|c|c|c|c|}
\hline & Boys $(\mathrm{N}=308)$ & Girls $(\mathrm{N}=326)$ & $P$ value \\
\hline \multicolumn{4}{|l|}{ Nutrients } \\
\hline Energy (kcal) & $1823(1557,2139)$ & $1621(1337,1879)$ & $<0.001$ \\
\hline Protein $(g)$ & $47.6(43.3,51.7)$ & $44.6(40.4,48.8)$ & $<0.001$ \\
\hline Fat $(g)$ & $45.5(39.0,52.2)$ & $42.2(36.6,48.9)$ & $<0.001$ \\
\hline Carbohydrate (g) & $284.2(239.2,332.2)$ & $250.1(200.2,291.3)$ & $<0.001$ \\
\hline Protein (\% energy) $*$ & $11.1(10.0,12.4)$ & $11.2(10.1,12.4)$ & 0.821 \\
\hline Fat (\% energy) $*$ & $24.1(21.9,27.4)$ & $25.2(21.9,28.0)$ & 0.063 \\
\hline Carbohydrate (\% energy) $*$ & $64.7(60.9,68.0)$ & $64.0(60.5,67.2$ & 0.106 \\
\hline Thiamine (mg) & $0.92(0.82,1.04)$ & $0.89(0.77,0.99)$ & 0.002 \\
\hline Riboflavin (mg) & $0.89(0.84,0.93)$ & $0.86(0.82,0.92)$ & $<0.001$ \\
\hline Niacin (mg) & $11.46(9.71,13.67)$ & $10.32(8.69,12.06)$ & $<0.001$ \\
\hline Vitamin $\mathrm{B}_{6}(\mathrm{mg})$ & $1.32(1.29,1.36)$ & $1.30(1.27,1.33)$ & $<0.001$ \\
\hline Vitamin $B_{12}(\mu g)$ & $0.96(0.68,1.36)$ & $0.87(0.67,1.28)$ & 0.055 \\
\hline Folate $(\mu \mathrm{g})$ & $191.0(147.4,235.2)$ & $176.3(139.6,226.3)$ & 0.026 \\
\hline Vitamin A ( $\mu g$ RAE) & $225.4(207.3,241.7)$ & $222.2(203.1,240.1)$ & 0.073 \\
\hline Iron $(\mathrm{mg})$ & $14.7(12.1,19.4)$ & $13.1(11.4,17.0)$ & $<0.001$ \\
\hline \multicolumn{4}{|l|}{ Food groups } \\
\hline Cereals $(g)$ & $270.8(216.0,320.9)$ & $221.0(174.1,269.3)$ & $<0.001$ \\
\hline Pulses (g) & $38.7(25.2,57.4)$ & $39.6(25.0,55.4)$ & 0.852 \\
\hline Root vegetables (g) & $32.3(13.1,59.8)$ & $30.5(14.5,53.9)$ & 0.569 \\
\hline Other vegetables $(\mathrm{g})$ & $119.5(79.7,184.7)$ & $116.2(80.4,158.2)$ & 0.158 \\
\hline Fruits (g) & $35.0(2.8,81.8)$ & $48.9(6.4,100.0)$ & 0.124 \\
\hline Milk (g) & $201.5(117.5,307.3)$ & $179.7(102.8,282.4)$ & 0.032 \\
\hline $\operatorname{Egg}(g)$ & $0(0,5.5)$ & $0(0.9 .2)$ & 0.559 \\
\hline Meat, fish, poultry (g) & $0(0,47.4)$ & $0(0,31.6)$ & 0.061 \\
\hline Nuts $(g)$ & $13.4(7.1,22.1)$ & $10.8(5.9,17.8)$ & 0.009 \\
\hline
\end{tabular}




\begin{tabular}{|lccc|}
\hline Added fats $(\mathrm{g})$ & $26.1(18.7,35.3)$ & $23.4(16.9,31.2)$ & 0.008 \\
\hline Added sugar (g) & $17.8(11.9,28.1)$ & $15.0(9.4,25.8)$ & 0.008 \\
\hline $\begin{array}{l}\text { P value performed using Mann Whitney U test } \\
\text { *P value obtained using Independent samples t test. }\end{array}$ & \\
\hline
\end{tabular}

Although the risk of inadequate intakes was over $5 \%$ for all nutrients, except for protein in boys, the risk was higher in girls for protein, iron, thiamine, riboflavin, niacin, $B_{6}$ and $B_{12}$, but not for dietary folate and vitamin A intakes (Table 3).

Table 3

Risk of inadequate intake of protein and micronutrients by sex

\begin{tabular}{|c|c|c|c|}
\hline & \multicolumn{2}{|c|}{ Percentage at risk of inadequate intakes } & \multirow[t]{2}{*}{$P$ value* } \\
\hline & Boys $(\mathrm{N}=308)$ & Girls $(\mathrm{N}=326)$ & \\
\hline \multicolumn{4}{|l|}{ All children } \\
\hline Protein & 3.2 & 15.3 & $<0.001$ \\
\hline Thiamine & 21.8 & 33.1 & 0.001 \\
\hline Riboflavin & 37.7 & 48.8 & 0.003 \\
\hline Niacin & 24.7 & 42.0 & $<0.001$ \\
\hline Vitamin $\mathrm{B}_{6}$ & 6.2 & 13.5 & 0.001 \\
\hline Vitamin $\mathrm{B}_{12}$ & 76.6 & 82.5 & 0.041 \\
\hline Folate & 79.9 & 82.2 & 0.258 \\
\hline Vitamin A & 96.8 & 94.8 & 0.152 \\
\hline Iron & 29.5 & 57.6 & $<0.001$ \\
\hline
\end{tabular}

While examining the proportion of children with intakes of carbohydrate, protein and fat as percent energy below or above the AMDR (Figure 1), overall $36 \%$ of the children had high intake for carbohydrate, $23 \%$ and $52 \%$ had low intake for protein and fat respectively. Among all children, low fat intake (OR:1.84; $95 \% \mathrm{Cl}: 1.14,2.98, \mathrm{p}=0.013)$, low protein intake (OR:1.73; 95\% Cl:1.05, 2.87, $\mathrm{p}=0.033$ ), and high carbohydrate intake (OR:2.16; $95 \% \mathrm{Cl}: 1.36,3.45, \mathrm{p}=0.001)$ were associated with underweight. Among girls, high carbohydrate intake (OR:3.11; 95\% Cl:1.55, 6.24, $\mathrm{p}=0.002)$ and low fat intake (OR:2.15; 95\% Cl:1.06, 4.35, $p=0.041$ ) were significantly associated with underweight but not for boys. No significant associations with macronutrients were observed either in overweight boys or girls. 
The association between tertiles of food group intake with weight categories was also performed by sex (Figure 2). In boys, the proportion of underweight children were higher in the lowest tertiles of vegetables intake (OR-2.71 95\% C. I. 1.11-6.58) but lower in the lowest tertile of fruit intake (OR-0.42; 95\%: 0.190.95). Higher proportion of underweight girls were in the lowest tertile of intake of roots OR-3.78, $95 \%$ C. I.1.31-10.8), nuts (OR-5.49, 95\% C. I. $1.71-17.6)$, milk products (OR-3.28, 95\% C. I. $1.03,10.5)$ and added sugar (OR-3.00, 95\%C. I. 1.10, 8.16).

A higher proportion of overweight boys was observed in the lowest tertile of pulse intake (OR-2.92; 95\% C. I.:1.31, 6.54); but a lower proportion in the lowest tertile of nut (OR-0.38; 95\% C. I.:0.17-0.86), and milk (OR: $0.40 ; 95 \%$ C. I. $0.18-0.91$ ) intake. Overweight girls were less likely in the lowest tertile of vegetable intake (OR-0.32, 95\% C. I. $0.14,0.70)$ and more likely in lowest tertile of meat intake (OR-2.32; $95 \%$ C. I.: 1.12-4.42). Added sugar intake was not significantly different between underweight and normal or overweight children and normal children both in boys $(4.4 \mathrm{~g}, 4.5 \mathrm{~g}$ and $4.4 \mathrm{~g}$ in underweight, normal and overweight respectively) and girls $(4.4 \mathrm{~g}, 4.6 \mathrm{~g}$ and $4.6 \mathrm{~g}$ in underweight, normal and overweight respectively).

Fortified foods were consumed by $55 \%$ of the children. About $65 \%$ of overweight, $45 \%$ of underweight and $54 \%$ of normal weight children consumed fortified foods. The consumption of fortified foods among overweight children $(65 \%)$ was significantly higher $(p=0.016)$ as compared to underweight and normal weight children. All children consumed breakfast. About $25 \%$ of daily total macronutrient intake was from breakfast. There was no significant difference in breakfast intakes between the various categories of weight status. Vitamin and mineral supplements were taken by less than $1 \%$.

\section{Discussion}

Food intake data of 634 school going children aged 8 to 15 years was examined stratified by sex through a cross-sectional study. There is not much evidence on food and nutrient intakes in children in India. Although the National Nutrition Monitoring Bureau (NNMB 2011-12) (39) does provide data on dietary intakes of children up to 18 years of age in rural areas, these are based on household consumption using consumer units rather than individual consumption. Nevertheless, based on the energy required for this age group of children at $64 \mathrm{kcal} / \mathrm{kg} \mathrm{kcal} / \mathrm{kg}$ for boys and $58 \mathrm{kcal} / \mathrm{kg}$ for girls, our study population had an intake of about $50 \mathrm{kcal} / \mathrm{kg}$ for boys and $45 \mathrm{kcal} / \mathrm{kg}$ for girls. Although this may seem lower than the requirement, it should be noted that studies have reported low physical activity levels in children in India $(23,40,41)$ and the requirement could be lower as these are set based on the assumption that children have a moderate level of activity.

In our study, the percent of energy contributed by macronutrient intakes was not significantly different between boys and girls. That macronutrient intakes are higher among boys is not surprising as the difference in rates of growth and the change in fat mass and fat free mass warrant a higher requirement among males (21). Sex (biological or physiological characteristics) or gender-based (socio-cultural aspects, behaviours and attitudes) differences in diet intakes and behaviours have been noted in a few 
studies in adult men, women and children (22-27). In a study conducted in Canada, it was reported that men reported higher intakes of energy, increased energy density and a higher percentage of energy consumed from fats and a decreased score for emotional susceptibility to disinhibition compared to women (28). A food choice favouring high energy foods is likely to lead to weight gain and subsequently to overweight and obesity (29). The physiological controls for eating and energy homeostasis are purportedly different between the sexes although delineating the differences between biological and nonbiological causes is difficult (30). In a study across 23 countries, it was reported that women reportedly chose lesser high fat foods, more high fibre foods and fruits with $50 \%$ of the food choice based on health beliefs and $20 \%$ on dieting status $(30,31)$. The choice of food and composition of the diet are generally culture specific (20); but the type and quality of diet affect the weight status (22). Differences in consumption among male and female children, however, has not been explored in other countries.

In general, the risk of inadequate intakes was high for most micronutrients examined, with the highest reported for vitamin $A$, folate, $B_{12}$ and iron. This is certainly a matter of concern implying that efforts to improve or diversify diet intakes is essential. Inadequate intakes of protein, iron and the $B$ vitamins, except for folate and $\mathrm{B}_{12}$ were significantly higher in girls compared to boys. Thus, the micronutrient density of the diets of school-going children is inadequate to meet requirements and education to both the child and the family on methods to improve nutrient density of diets is required. The inadequacy of intake of micronutrients has not been conclusively demonstrated earlier among school going children in India as diets were analysed using household consumption units and not using an individual's dietary data using 24-hour dietary recalls, estimates of which are closer to the true value of consumption.

That over $50 \%$ of children had low intakes of fat and $23 \%$ for protein compared to the recommendations for the acceptable macronutrient range is a matter of concern as it indicates a low diet quality. The association of low fat and protein intakes and high carbohydrate intakes with underweight, accentuates this finding further and implies that carbohydrate intakes largely contributed by cereals is higher in those underweight, as diverse diets are probably costlier (3).

In our study, overweight boys consumed a higher percentage of energy from proteins and lesser percentage of energy from carbohydrates rather than increasing their fat percentage from energy. This was largely through increase in intake of milk and milk products, and nuts and an upward trend towards consumption of eggs, fish and meat rather than an increased consumption of pulses. But this finding needs to be validated further as even with lower intakes compared to the developed countries an association has been shown. A similar observation was observed among school aged children in Germany where children with medium or high protein intakes had higher BMI z scores than those with low protein intakes (32). This could translate to a higher lean body mass in boys. In girls, the proportion of children being in the highest tertile of carbohydrate intake and lowest tertile of fat intake was significantly higher.

Among these children $13.7 \%$ were underweight and $18.8 \%$ overweight. The rising trend in overweight and obesity has been noted in a review of studies of overweight and obesity in children 1-18 years of age,

Page $11 / 19$ 
conducted between 1980 to 2013 across 16 states in India (33). Compared to a prevalence of about 16.3 $\%$ between years 2001 and 2005, in studies conducted after the year 2010, the prevalence reached about $19.3 \%$. A variability in prevalence rates were noted across studies. A more recent review of 21 studies across 11 states of India indicated a range of prevalence from $1.5 \%$ to $32.2 \%$, with higher rates in boys and in children living in the urban area. Our earlier study in a similar urban population aged 7 to 15 years in Bangalore showed a prevalence of $7.2 \%$ overweight and 1\% obese in the year 2005 (34). The present study conducted a decade later has shown a substantial increase in overweight and obesity in school children. With childhood overweight and obesity rates increasing across socio-economic groups in urban areas, there is a need to plan public health programmes accordingly as it is likely to track to adulthood and to later chronic disease $(5,35)$.

Further, prevalence of overweight and obesity among women is much higher compared to men as per the latest National Family Health Survey (NFHS 4) (36), a phenomenon observed across all the continents. In a review of overweight and obesity in children across several countries (37) a similar trend was seen where prevalence was higher in female children. However, in our study on school going children, this difference between boys and girls was not observed The fact that there are substantial increases in overweight and obesity levels in school going children as compared to children below the age of 5 years as reported in NFHS $4(\sim 2.0 \%)$, indicates that the problem is likely to exacerbate further with obesity tracking into adulthood and probably further escalating the problem of non-communicable diseases in India.

There is a possibility that overweight children consistently underreport their intakes and hence associations are not evident. Although it has been noted that children's accuracy for reporting items and amounts improved with multiple recalls, discrepancies in reporting varied across individual children with underreporting increasing with increase in BMI (38-41). The accuracy of reporting was also found to be better among females than males (39).

The strength of the study is that it is representative of children from different socio-economic strata of society and included diet intakes of children with weight status ranging from underweight to overweight. Most studies on diet intakes are from the developed countries which have marginal rates of undernutrition, and not from a developing country. Capturing individual diets of children across India is required to understand how children eat, the nutrient density and inadequacy of their diets.

A primary limitation, however, is that data capturing diet intakes cannot be without errors. It has also been reported (42) that children do have the ability to participate in recalls without any assistance, but the recall needs to be in the last 24 hours. However, the method of collection and the reporting by subjects influence the nature and quantum of error (18). The study used three 24-hour recalls adjusted for withinand between-person estimates using statistical techniques for nutrients of interest $(16,18)$, that can provide an intake value closer to the true intake of the population group and thus is a valid measure of dietary intake. The data was also collected over a period of one school year thus reducing the degree of error. 
Another limitation of the study was that physical activity was not captured and thus activity levels could not be adjusted for in this analysis. Although subjective measures of dietary data collection using a standardized protocol were used, the likelihood of underreporting and/or misreporting is possible as reported in other studies $(43,44)$. With the study being cross-sectional, conclusions on cause-and-effect relationships and the direction of the associations observed cannot be made.

The fact that a large proportion of overweight children used fortified foods needs to be explored further. Unlike other countries, all children consumed breakfast and there was no association with the percentage of macronutrient intake consumed through breakfast with weight categories. Similar studies also need to be conducted across different states in India as the extent of nutrition transition can be different across states.

It should be noted that it is difficult to decipher whether the differences between girls and boys can be attributed to biological factors related to sex or social factors related to gender. It is most likely that both factors contribute to these differences $(22,37)$.

\section{Conclusion}

There is a dearth of data on nutrient and food intakes of children in India, A significant difference in nutrient and food group intake was observed between male and female children in India. Overall, energy intakes were lower in this population of children from the urban area. The risk of inadequate intake of protein and micronutrients were high especially for vitamin $A$, folate, vitamin $B_{12}$ and iron. Except for vitamins $B_{12}$ and $A$, all other nutrients were different between males and females. About $50 \%$ of children had fat intakes below the AMDR. In general, the quality of diets in children need to be improved to reduce underweight and arrest the increase in overweight and obesity in children which is likely to track into adulthood. Public health programmes combining messages on healthy eating and adequate physical activity need to be designed to address the double burden of malnutrition through extensive school and community-based education programmes.

\section{Declarations}

Ethics approval and consent to participate: The methods section of the manuscript includes these details.

Acknowledgements: The authors wish to acknowledge the school principals, the participants and their parents for their support and cooperation during the study.

Author's contributions: SS, TT and AVK designed the study. SS analyzed and interpreted the data and critically revised the manuscript. KGJ coordinated the data collection, entry and partly analyzed the data. SSe performed the statistical analysis and interpreted the data. All authors, helped draft, critically revise the manuscript and approved the final manuscript. 
Source of funding: Funded by GlaxoSmithKline Consumer Healthcare Ltd. The funders were not involved in the design and implementation of the study.

Competing interests: The authors declare that they have no competing interests.

Additional file: Supplementary file with tables, Strobe checklist.

Consent for publication: Not applicable

Availability of data and materials: All data generated or analysed during this study are included in this published article [and its supplementary information files].

Author information: SS, SSe and KGJ: St John's Research Institute, Bangalore, India; TT, AVK: St John's Medical College, Bangalore, India

\section{References}

1. Popkin BM. Global nutrition dynamics: The world is shifting rapidly toward a diet linked with noncommunicable diseases. Am J Clin Nutr. 2006;84(2):289-98.

2. Cuevas Garciá-Dorado S, Cornselsen L, Smith R, Walls H. Economic globalization, nutrition and health: A review of quantitative evidence. Global Health. 2019;15(1):1-19.

3. UNICEF. The state of the world's children 2019. Children, food and nutrition: Growing well in a changing world. New York: UNICEF; 2019.

4. Shetty PS. Nutrition transition in India. Public Health Nutr. 2002;5(1A):175-82.

5. Misra A, Singhal N, Sivakumar B, Bhagat N, Jaiswal A, Khurana L. Nutrition transition in India: Secular trends in dietary intake and their relationship to diet-related non-communicable diseases. J Diabetes. 2011;3(4):278-92.

6. Vaz M, Yusuf S, Bharathi AV, Kurpad A V., Swaminathan S. The nutrition transition in India Dietary profiles in India. South African J Clin Nutr. 2002;198-201.

7. Aurino E, Fernandes M, Penny ME. The nutrition transition and adolescents' diets in low- and middleincome countries: A cross-cohort comparison. Public Health Nutr. 2017;20(1):72-81.

8. Ochola S, Masibo PK iny. Dietary intake of schoolchildren and adolescents in developing countries. Ann Nutr Metab. 2014;64:24-40.

9. Manyanga T, Tremblay MS, Chaput JP, Katzmarzyk PT, Fogelholm M, Hu G, et al. Socioeconomic status and dietary patterns in children from around the world: Different associations by levels of country human development? BMC Public Health. 2017;17(1):1-11. 
10. Murphy SP, Vorster HH. Methods for using nutrient intake values (NIVs) to assess or plan nutrient intakes. Food Nutr Bull. 2007;28(1 SUPPL. 1):51-60.

11. Indian Council of Medical Research. Nutrient requirements and recommended dietary allowances for Indians. A report of the expert group of the Indian Council of Medical Research. Expert Group of the Indian Council of Medical Research. Hyderabad, India: Nationaal Institute of Nutrition, ICMR; 2010. 1-334 p.

12. National Nutrition Monitoring Bureau. Prevalence of micronutrient deficiencies. Hyderabad, India: Nationaal Institute of Nutrition, ICMR; 2003.

13. Government of India. India in figures 2018 [Internet]. New Delhi: Social Statistics Division, Central statistics office, Ministry of statistics and programme implementation, Government of India; 2018. Available from: www.mospi.gov.in

14. Burrows TL, Martin RJ, Collins CE. A Systematic Review of the Validity of Dietary Assessment Methods in Children when Compared with the Method of Doubly Labeled Water. J Am Diet Assoc [Internet]. 2010;110(10):1501-10. Available from: http://dx.doi.org/10.1016/j.jada.2010.07.008

15. Bharathi AV, Kurpad AV, Thomas T, Yusuf S, Saraswathi G, Vaz M. Development of food frequency questionnaires and a nutrient database for the Prospective Urban and Rural Epidemiological (PURE) pilot study in South India: methodological issues. Asia Pac J Clin Nutr. 2008;17(1):178-85.

16. Institute of Medicine. Dietary Reference Intakes. The essential guide to nutrient requirements. Otten JJ, Hellwig JP, Linda D, editors. Washington, D.C: Food and Nutrition Board, Institute of Medicine; 2006. 0-309 p.

17. Institute of Medicine. Dietary reference intakes: Applications in dietary assessment. A Report of the Subcommittee on Interpretation and Uses of Dietary Reference Intakes and the Standing Committee on the Scientific Evaluation of Dietary Reference Intakes. Washington, D.C: Food and Nutrition Board, Institute of Medicine; 2000. 1-306 p.

18. Beaton GH. Approaches to analysis of dietary data: relationship between planned analyses and choice of methodology. Am J Clin Nutr. 1994;(59):253S-261S.

19. Ghosh S, Sinha S, Shivakumar N, Thomas T, Sachdev HS, Kurpad A V. Daily Iron Requirements in Healthy Indian Children and Adolescents. Indian Pediatr. 2019;56(7):551-5.

20. de Onis M, Onyango AW, Borghi E, Siyam A, Nishida C, Siekmann J. Development of a WHO growth reference for school-aged children and adolescents. Bull World Health Organ. 2007;85(9):660-7.

21. Cheng HL, Amatoury M, Steinbeck K. Energy expenditure and intake during puberty in healthy nonobese adolescents: A systematic review. Am J Clin Nutr. 2016;104(4):1061-74. 
22. Varì R, Scazzocchio B, Papa S Del. Dietary habits and gender differences. Ital J Gender-Specific Med. 2017;3(2):55-8.

23. Li KK, Concepcion RY, Lee H, Cardinal BJ, Ebbeck V, Woekel E, et al. An Examination of Sex Differences in Relation to the Eating Habits and Nutrient Intakes of University Students. J Nutr Educ Behav [Internet]. 2012;44(3):246-50. Available from: http://dx.doi.org/10.1016/j.jneb.2010.10.002

24. Leblanc V, Begin C, Corneau L, Dodin S, Lemieux S. Gender differences in dietary intakes: what is the contribution of motivational variables? J Hum Nutr Diet. 2015;28:37-46.

25. Kabir A, Miah S, Islam A. Factors influencing eating behavior and dietary intake among resident students in a public university in Bangladesh: A qualitative study. PLoS One. 2018;13(6):1-17.

26. Kanter R, Caballero B. Global gender disparities in obesity: A Review. Adv Nutr. 2012;3:491-8.

27. Keller KL, Kling SMR, Fuchs B, Pearce AL, Reigh NA, Masterson T, et al. A biopsychosocial model of sex differences in children's eating behaviors. Nutrients. 2019;

28. Leblanc V, Hudon AM, Royer MM, Corneau L, Dodin S, Bégin C, et al. Differences between men and women in dietary intakes and metabolic profile in response to a 12-week nutritional intervention promoting the Mediterranean diet. J Nutr Sci. 2015;4:1-11.

29. Manippa V, Padulo C, van der Laan LN, Brancucci A. Gender differences in food choice: Effects of superior temporal sulcus stimulation. Front Hum Neurosci. 2017;11(December):1-9.

30. Asarian L, Geary N. Sex differences in the physiology of eating. Am J Physiol Regul Integr Comp Physiol 305. 2013;305:R1215-R1267.

31. Wardle J, Haase AM, Steptoe A, Nillapun M, Jonwutiwes K, Bellisle F. Gender differences in food choice: The contribution of health beliefs and dieting. Ann Behav Med. 2004;27(2):107-16.

32. Pei Z, Flexeder C, Fuertes E, Standl M, Buyken A, Berdel D, et al. Food intake and overweight in schoolaged children in Germany: Results of the GINIplus and LISAplus Studies. Ann Nutr Metab. 2014;64(1):6070.

33. Ranjani H, Mehreen T, Pradeepa R, Anjana RM, Garg R, Krishnan A, et al. Epidemiology of childhood overweight \& obesity in India: A systematic review. Indian J Med Res. 2016;143(2):160-74.

34. Swaminathan S, Thomas T, Kurpad AV, Vaz M. Dietary patterns in urban school children in South India. Indian Pediatr. 2007;44(8):593-6.

35. Vaz M, Swaminathan S. Childhood Physical Activity, Sports and Exercise and Noncommunicable Disease: A Special Focus on India. The Indian Journal of Pediatrics. 2012. 
36. International Institute for Population Sciences I. National Family Health Survey (NFHS-4). Mumbai, India: IIPS; 2017. 199-249 p.

37. Sweeting HN. Gendered dimensions of obesity in childhood and adolescence. Nutr J. 2008;7(1):114.

38. Foster E, Bradley J. Methodological considerations and future insights for 24-hour dietary recall assessment in children. Nutr Res. 2018;51:1-11.

39. Baxter DS, Smith AF, Nichols MD, Guinn CH, Hardin JW. Children's dietary reporting accuracy over multiple 24-hour recalls varies by body mass index category. Nutr Res. 2006;26(6):241-8.

40. Perks SM, Roemmich JN, Sandow-Pajewski M, Clark PA, Thomas E, Weltman A, et al. Alterations in growth and body composition during puberty. IV. Energy intake estimated by the Youth-Adolescent FoodFrequency Questionnaire: Validation by the doubly labeled water method. Am J Clin Nutr. 2000;72(6):1455-60.

41. Fisher JO, Johnson RK, Lindquist C, Birch LL, Goran MI. Influence of body composition on the accuracy of reported energy intake in children. Obes Res. 2000;8(8):597-603.

42. Livingstone MBE, Robson PJ. Measurement of dietary intake in children. Proc Nutr Soc. 2000;59(2):279-93.

43. Livingstone MBE, Robson PJ, Wallace JMW. Issues in dietary intake assessment of children and adolescents. Br J Nutr. 2004;92(S2):S213-22.

44. Papandreou D, Makedou K, Zormpa A, Karampola M, loannou A, Hitoglou-Makedou A. Are dietary intakes related to obesity in children? Open Access Maced J Med Sci. 2016;4(2):194-9.

\section{Figures}




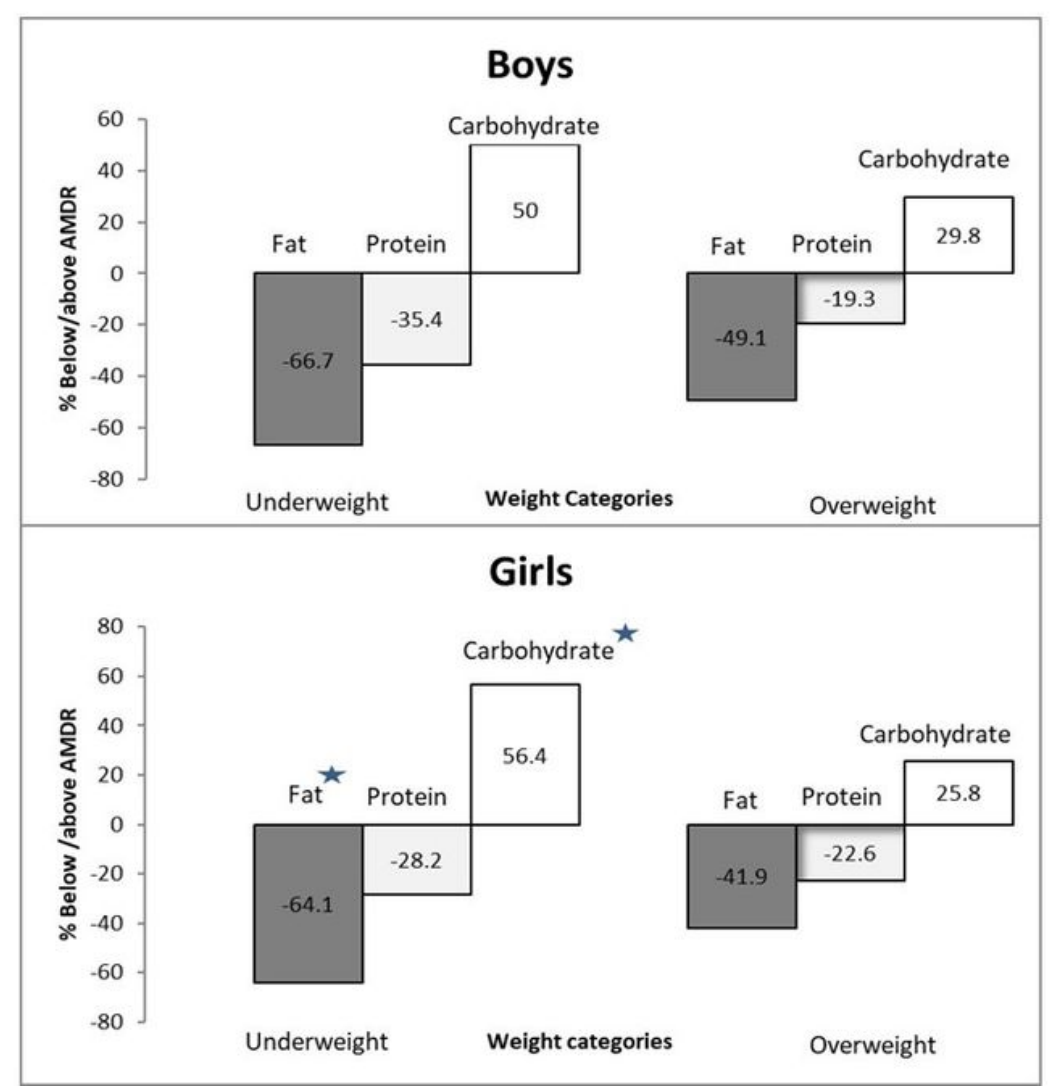

\section{Figure 1}

Proportion of boys and girls with intakes lower or higher than the recommended Acceptable Macronutrient Distribution Range (AMDR). Percentage energy contributed by fat, protein and carbohydrate in underweight, and overweight children is represented. The values below 0 indicates proportion lower than recommended and above 0 higher than recommended; * $p<0.05$ 

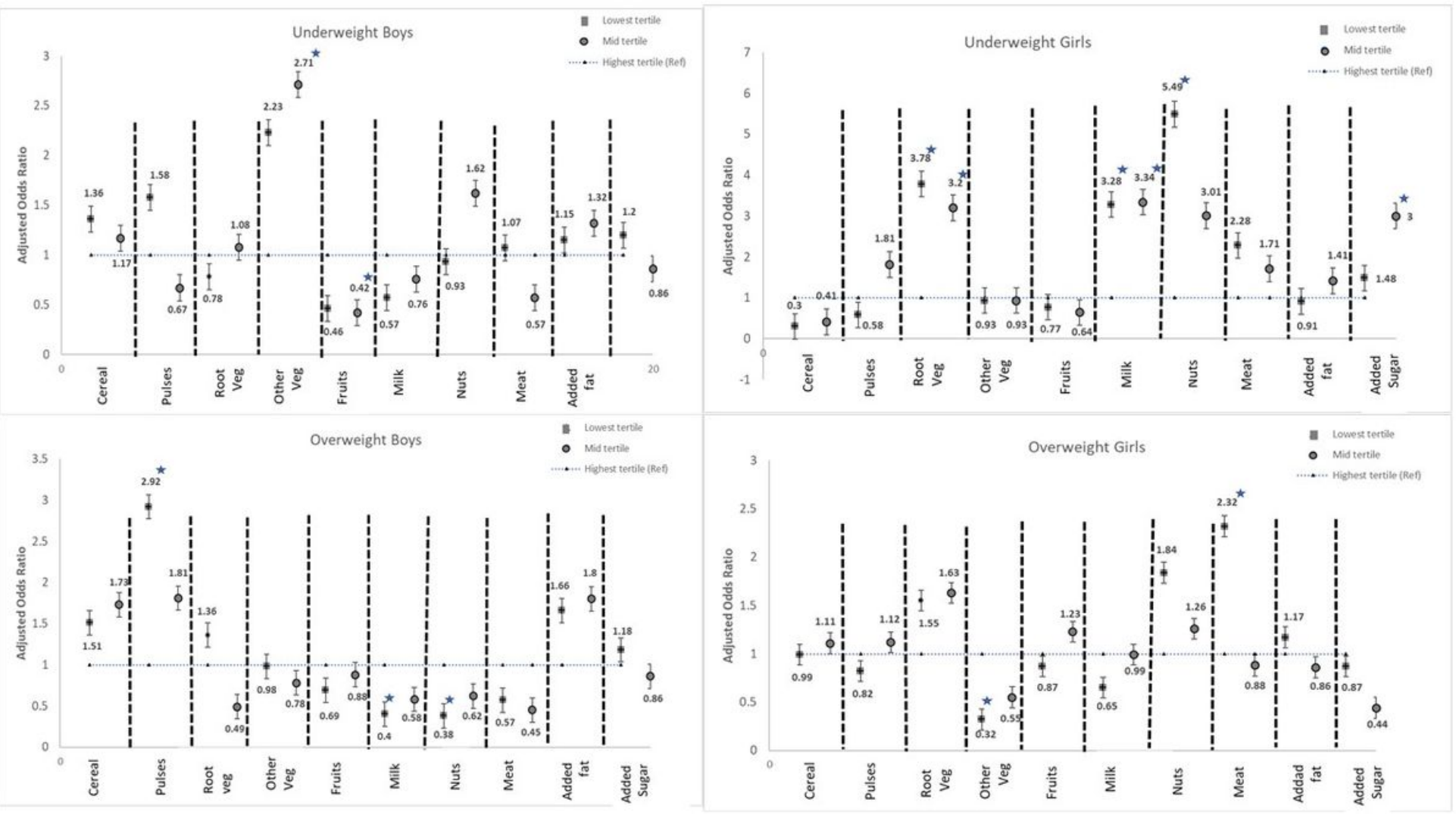

Figure 2

Adjusted OR for the association between food group intake tertiles and being underweight and overweight in boys and girls. Data for 10 food groups adjusted for age and energy intake is shown. The dotted line at 1 in $\mathrm{Y}$ axis indicates the reference line which is the highest tertile of intake. The adjusted odds ratio $(95 \% \mathrm{Cl})$ is represented as error bars for the lower and mid tertiles for each weight category. * $p$ $<0.05$.

\section{Supplementary Files}

This is a list of supplementary files associated with this preprint. Click to download.

- SupplementaryDietaryintakesassocwithweightstatus.docx 